\title{
Bristol Stool Type 4
}

National Cancer Institute

\section{Source}

National Cancer Institute. Bristol Stool Type 4. NCI Thesaurus. Code C125397.

Like a smooth, soft sausage or snake; normal stool. 